\title{
A Study Related To Mental Health of Teachers With Reference To Level of Teaching and Teaching Experience
}

\author{
Dr.D.MOHANA, Associate Professor, \\ Education Wing (DDE), Annamalai University
}

\begin{abstract}
The Present study is focussed on the mental health of teachers in relation to level of teaching and teaching experience. The mental health scale has been administered to 640 teachers working in different schools in Cuddalore district, Tamil Nadu, India. This study uses ' $F$ ' test and reveals that the level of teaching and teaching experience do not significantly differ in their mental health.
\end{abstract}

\section{Introduction}

Education is a comprehensive and synthetic process, which helps in the development of the body, the nourishment of the mind, the sublimation of the emotions and regeneration of the spirit and its fulfilment lies in the unfolding of an integrated personality. Teaching is often said to be the noblest profession among all the professions so the teachers should realize that the work they are doing is the noblest and that they need not be apologestic or feel guilty ,instead have pride and confidence in their worth and work. Tagore rightly said that "only lighted lamp can lighten another" which means that only an enlightened teacher who remains ever alive and struggling in the pursuit of knowledge, could enlighten his pupil and could enthuse them for more learning. One of the important qualities in the educator is that he knows his subject thoroughly well and is to keep in touch with his subject to remain up-to-date. A good teacher is required to have an attitude of love and sympathy for children. The ideal character of teacher leaves an ever lasting impression on the minds of his pupil. It is the teacher who can create a national perspective for understanding social and economic difference in the nation. The teacher should be a model to his own image in the minds of his students. The present study seeks to throw light on the mental health of teachers. The objective of the study is to find out the mental health of teachers. The hypothesis of the research is that the mental health of teachers is high. The mental health of teachers belonging to different subsample is high. There is a significant difference in the mental health of teachers with respect to different sub-sample such as 1 .Teachers working at different levels of teaching 2.Teachers belonging to different years of teaching experience. The normative survey method is used. The present study is aimed at finding out the effect of the independent variables namely Level of teaching, Teaching experience. The following tools have been used for collecting data.1.Mental health Inventory standardized by Peter Becker(1989).Mental health inventory has been administered to a stratified random sample of 640 teachers working at different levels in various educational institutions in Cuddalore district, Tamil Nadu, India. The study is confined only to the teachers working in Cuddalore, district of Tamil Nadu.

\section{Review of Related Literature}

Robert Roser et al (1999) found that there is a relationship between mental health and achievement . Sri vastava(1999) inferred that there is significant difference between the mental health of Hindi and English medium students. Alli(2001) found that the mental health of students studying in government and private, rural and urban schools do not differ significantly .Sivaguru(2002) observed that the attitude towards teaching and their mental health is significantly related to each other.

Clavos and Bedregal (2002) conducted a study on mental health status of teachers. The result revealed that the numbers of working hours were directly related to mental health problems.

Elisa Epel(2002) conducted a study on mental health and ageing. The study revealed that chronic stress and suffering women shows more ageing.

\section{Method Of Study}

The mental health inventory standardized by Peter Becker (1989) has been used to measure the mental health of teachers. It is four-point scale. It includes 20 statements .Each statement has four alternative responses namely 'always', 'often', 'Sometimes', and 'never'. For positive statements the four responses were given a weightage of 4 to 1 respectively for always, often, sometimes, and never. For negative statements the reverse order was followed. A subject can get a maximum of 80.There is no time limit for completion. However it takes 15 to 20 minutes to complete the task. The reliability of the tool has been found out by the test-retest method. It is found to be 0.81 .The validity of the Peter Becker's mental health inventory inventory has been ascertained by the experts. 


\begin{tabular}{|c|c|c|}
\hline Sl.NO. & Level of teaching & Total \\
\hline 1. & Primary & 177 \\
\hline 2. & Secondary & 155 \\
\hline 3. & Higher Secondary & 198 \\
\hline 4. & College & 130 \\
\hline & Total & 640 \\
\hline
\end{tabular}

Fig 3.1 Distribution of the Sample on the Basis of Level of Teaching

From the above Fig 3.1 it is seen that the sample includes 177 primary school teachers, 155 secondary school teachers, 198 higher secondary school teachers and 130 college teachers

\begin{tabular}{|l|l|l|}
\hline Sl.NO & $\begin{array}{l}\text { Teaching } \\
\text { Experience }\end{array}$ & Total \\
\hline 1. & Below 5 Years & 255 \\
\hline 2. & 6-10 Years & 167 \\
\hline 3. & $11-15$ Years & 82 \\
\hline 4. & $\begin{array}{l}\text { Above 16 } \\
\text { Years }\end{array}$ & 136 \\
\hline & Total & 640 \\
\hline
\end{tabular}

Fig 3.2 Distribution of the sample on the basis of Teaching Experience

From the above Fig 3.2 it is seen that the sample includes 255 teacher having below five years of teaching experience, 167 teachers having six to ten years of experience, 82 teachers having eleven years to fifteen years of experience and 136 teachers having above 16 years of experience

\section{Analysis Of Data}

The mean and standard deviation for the metal health scores is given in Table 4.6 .The mean and standard deviation of the total group are 55.02 and 8.29 respectively. The maximum score given for the tool is 80.hence it can be inferred that the mental health of teachers is high .The larger value of the standard deviation indicates a wide dispersion of scores around the mean. Percentiles are calculated (Table 4.5).It is seen that fifty percent of the teachers have scored below 55.To sum up, the following conclusion is reached in respect of the hypothesis .The mental health of teachers is high.

\begin{tabular}{|l|l|}
\hline Percentile & Value \\
\hline$P_{10}$ & 45 \\
\hline$P_{20}$ & 48 \\
\hline$P_{30}$ & 51 \\
\hline$P_{40}$ & 53 \\
\hline$P_{50}$ & 55 \\
\hline$P_{60}$ & 57 \\
\hline$P_{70}$ & 59 \\
\hline$P_{80}$ & 60 \\
\hline$P_{90}$ & 64 \\
\hline
\end{tabular}

Fig 4.1 Percentile for Mental Health Scores

To sum up, the following conclusion is reached in respect of the hypothesis. The mental health of teachers is high.

A more detailed of the mental health scores has been made by calculating the mean and standard deviation of the mental health scores of the teachers belonging to the different sub-samples .

\begin{tabular}{|c|c|c|c|c|}
\hline S.No & Sub-sample & Number & Mean & SD \\
\hline 1. & $\begin{array}{l}\text { Level of } \\
\text { Teaching }\end{array}$ & & & \\
\hline & Primary & 177 & 54.11 & 7.65 \\
\hline & Secondary & 135 & 56.22 & 8.76 \\
\hline & $\begin{array}{l}\text { Higher } \\
\text { Secondary }\end{array}$ & 198 & 55.14 & 8.39 \\
\hline & College & 130 & 54.83 & 8.42 \\
\hline 5. & $\begin{array}{l}\text { Teaching } \\
\text { Experience }\end{array}$ & & & \\
\hline & $\begin{array}{l}\text { 5years and } \\
\text { below }\end{array}$ & 255 & 55.14 & 8.11 \\
\hline & $6-10$ years & 167 & 56.10 & 8.20 \\
\hline
\end{tabular}




\begin{tabular}{|l|l|l|l|l|}
\hline & $11-15$ years & 82 & 54.97 & 9.23 \\
\hline $\begin{array}{l}16 \text { years and } \\
\text { above }\end{array}$ & 136 & 53.50 & 8.01 \\
\hline
\end{tabular}

Fig 4.2 Mean and Standard Deviation for Mental Health Scores of Teachers

The $\mathrm{F}$ test is applied to find out whether the teachers belonging to different levels of teaching differ significantly in their mental health

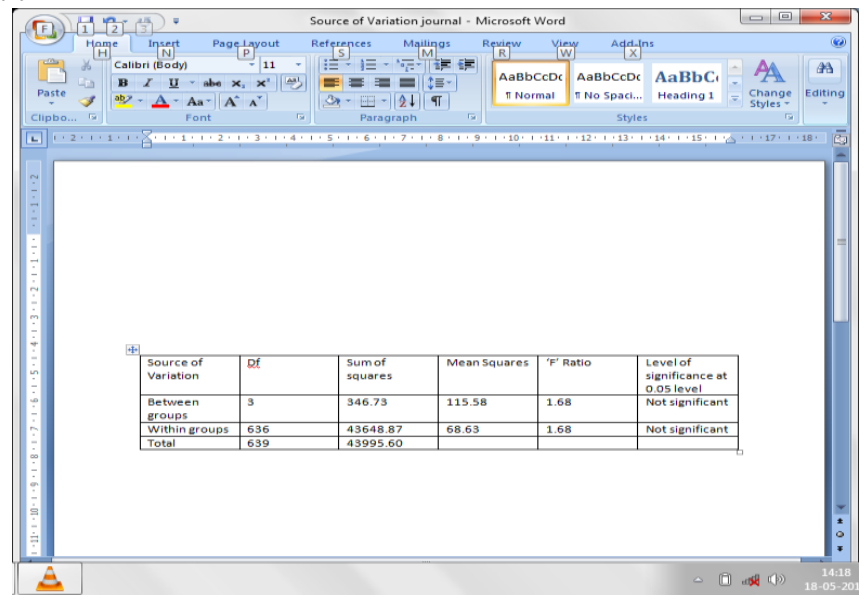

Fig 4.3 'F' Ratio for Level of

\section{Teaching And Mental Health}

It is clear from Fig 4.3 that $\mathrm{F}$ ratio is not significant at 0.05 level.Hence, the null hypothesis is accepted .The following conclusion is reached in the respect of the hypothesis. The teachers belonging to different levels of teaching do not significantly differ in their mental health.

\subsection{Teaching Experience and Mental Health}

The $\mathrm{F}$ test is applied to find out whether the teachers belonging to different years of teaching experience differ significantly in their mental health

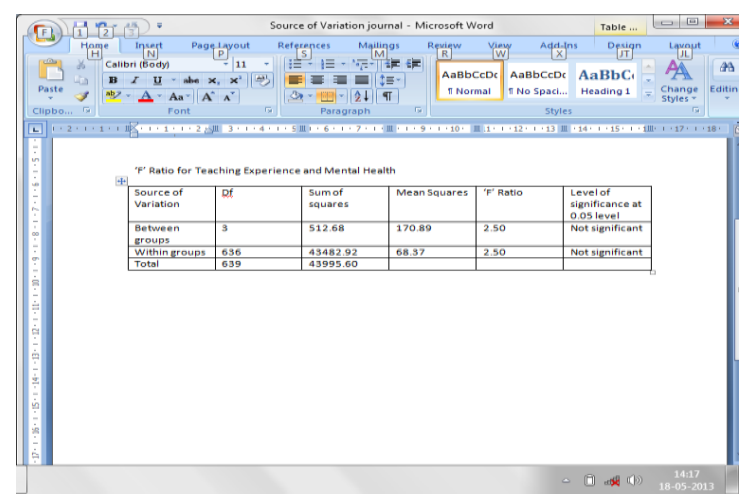

Fig 4.1.1 Teaching Experience and Mental Health

It is clear from Fig 4.1.1 that ' $\mathrm{F}$ ' ratio is not significant at 0.05 level .Hence the null hypothesis is accepted. The following conclusion is reached in respect of the hypothesis. The teachers belonging to different years of teaching experience do not significantly differ in their mental health.

\section{FINDINGS}

The Teachers belonging to different level of teaching and teaching experience do not significantly differ in their mental health.

\section{Recommendations}


It is obligatory on the part of the teacher to teach effectively in required time with the help of the available resources. The teacher should abide by the rules and regulations of the institutions provided by the higher authorities from time to time. They should act as a link between higher authorities and students.

\section{Biblography}

[1]. Clavos Bedregal, 2002.Mental Health Status of Teachers .Ph.D.Thesis, Yale University.

[2]. Elisa Epel, 2002.Mental Health and Aging.Ph.D Thesis, California University.

[3]. Srivastava,S.K., 1999.A Study of Mental Health of Hindi and English Medium Students .Journal of Educational Research and Extension, vol.35(3),23-28.

[4]. Sivaguru, m., 2002. A Study of Teachers Attitude towards Teaching in Relation to their Mental Health. Unpublished M.Phil.Thesis, Annamalai University.

[5]. Aurin et al.Forms and Dimensions of Teachers Professional Ethics: Case studies in Secondary Schools. Journal of Moral Education, Vol 22 (3), 277-296,1993.

[6]. Brophy Herb Holly, E. A Development Approach to Teaching about Ethics using NAEYC. Code of Ethical Conduct, vol 56, (1),8084,2001 . 